\title{
Three Decades and Counting: HIV Service Provision in Outpatient Mental Health Settings
}

Karen McKinnon, M.A., James Satriano, Ph.D., Jean-Marie Alves-Bradford, M.D., Whitney Erby, M.A., Fatima J. Jaafar, B.S., Elizabeth H. Simonen, M.A., Izabella S. Gozzo, Amy N. Robles Huang, Jonah S. Sposito, Ziyi Tao, Martin J. Zakoian, Alma Zurita McKinnon, Francine Cournos, M.D.

\begin{abstract}
Objective: People with serious mental illness in the United States have higher human immunodeficiency virus (HIV) infection rates than the general U.S. population. This study aimed to assess delivery of HIV services in New York State's outpatient mental health programs. Greater access would enhance efforts to improve HIV prevention and care outcomes.

Methods: The authors surveyed directors of licensed outpatient mental health care programs statewide to investigate their HIV service delivery. Data were compared with surveys conducted in 1997 and 2004 in order to examine differences in services between geographic regions and time periods.
\end{abstract}

Results: Outpatient mental health programs have improved in the volume and range of HIV services offered, but their provision of preexposure prophylaxis, condoms, HIV testing, and HIV antiretroviral treatment monitoring has lagged.

Conclusions: New York's initiative to end the HIV epidemic is not optimized to reach people with serious mental illness in settings designed for their care.

Psychiatric Services 2020; 71:726-729; doi: 10.1176/appi.ps.201900415
The human immunodeficiency virus (HIV) infection rate in the United States is $0.4 \%$ among the general population (1) and $6.0 \%$ among people with serious mental illness (2). Serious mental illness refers to diagnoses that are disabling, persistent, and typically require specialized inpatient or outpatient psychiatric treatment; they include schizophrenia, schizoaffective disorder, and bipolar disorder (3).

New York State, a major epicenter of HIV infection in the United States, has innovative programs to address the HIV epidemic. In 2010, the state legislated that routine HIV testing must be offered in most primary care encounters for people between ages 13 and 64 during inpatient, but not outpatient, psychiatric admissions (https://wwwl.nyc. gov/site/doh/providers/health-topics/aids-hiv-testing-law. page). In 2014, the state's Department of Health initiated the Ending the Epidemic (ETE) plan to reduce by the end of 2020 the number of new HIV infections (4) by diagnosing undiagnosed individuals, linking them to care, and initiating antiretroviral treatment; by improving patients' retention in treatment in order to attain an undetectable viral load; and by providing preexposure prophylaxis (PrEP) to at-risk people so that they remain HIV negative.

Examining the impact of New York's ETE efforts on people with serious mental illness would inform future programming. Surveys over the past 2 decades (5-7) found low rates of risk behavior assessment and HIV testing-and of referrals for both-in outpatient mental health settings in New York. Rates of HIV testing in this population are just under 7\% (8).

Barriers to integrating services include the complexity of treatments for both HIV and serious mental illness, which are often treated in separate systems of care (9). Studies suggest that HIV medical providers are more likely to deliver integrated HIV and mental health services than are providers working in mental health settings (10). Integration of behavioral and primary care services improves client outcomes (11) and reduces health care costs (12).

\section{HIGHLIGHTS}

- In the United States, prevalence of human immunodeficiency virus (HIV) infection among people with serious mental illness is exponentially higher $(6.0 \%)$ than in the general population $(0.4 \%)$

- HIV services in outpatient mental health settings are not optimized.

- Outpatient mental health settings must be included in efforts to end the HIV epidemic. 
The ETE Dashboard displays metrics on New York's progress toward achieving its ETE plan goals. The dashboard indicates that 91\% of estimated HIV-positive individuals have been diagnosed. Seventy percent of those diagnosed are in continuous care, and $81 \%$ of that subset have achieved viral suppression, critical for stopping HIV transmission. New York has fared better than the United States as a whole in suppressing the virus (13).

We surveyed all licensed outpatient mental health programs in the state to examine HIV-related services being delivered; service setting characteristics that support greater integration of HIV and mental health care; training needs of service providers; and current practices, compared with those in place earlier in the epidemic, to document progress in reaching this critical population with needed, although not mandated, HIV services.

\section{METHODS}

As part of an annual needs assessment for a training program funded by the Health Resources and Services Administration, in 2017 a questionnaire was sent to directors of all licensed outpatient mental health care programs in New York State seeking information about program characteristics, HIV services offered, provider training needs, and coordination of mental health and HIV care. Programs were contacted via an e-mail list of 434 program directors provided by the New York State Office of Mental Health, followed by two e-mail reminders over 3 months, resulting in 132 surveys completed online via Qualtrics. Some programs had closed or had been absorbed by larger programs, and some large programs with multiple sites and licenses responded with one survey. Eleven programs from the list were not contacted because of failed delivery $(\mathrm{N}=7)$, retirement of the director with no new director in place $(\mathrm{N}=3)$, and lack of clinical license $(\mathrm{N}=1)$. Thus, the response rate was $31 \%$, consistent with online survey response rates, which tend to be lower than rates for printed surveys (14).

\section{RESULTS}

Of the 132 responding programs, 55\% were in urban areas, $21 \%$ were suburban, and $24 \%$ were rural (Table 1). Sixtyseven percent $(\mathrm{N}=60)$ of programs in areas with moderate to high HIV case rates were in urban areas, $24 \%(\mathrm{~N}=22)$ were suburban, and $9 \%(\mathrm{~N}=8)$ were rural. Most programs $(\mathrm{N}=110$,
$83 \%)$ served over 200 clients annually; nearly all ( $N=116$, $-97 \%$ ) served clients who had co-occurring substance use disorders. Most programs (66\%) reported treating patients known to be HIV positive. Almost one-third (27\%) either treated no patients known to be HIV positive or were unable to estimate the number of HIV-positive patients in their programs. Nearly half of programs (46\%) reported that they treated one to 10 patients with HIV or AIDS, annually, and $23 \%$ served more than 100 patients with HIV or AIDS, annually.

Services provided included HIV educational materials ( $\mathrm{N}=62,60 \%)$, risk-reduction interventions ( $\mathrm{N}=49,47 \%), \mathrm{HIV}$ test counseling ( $\mathrm{N}=29,28 \%)$, support groups for HIVpositive clients $(\mathrm{N}=20,21 \%)$, and on-site HIV medical services $(\mathrm{N}=21,20 \%)$. Routine HIV risk assessment at intake occurred in $60 \%(\mathrm{~N}=60)$ of programs, and $33 \%$ offered HIV testing on site when risk was revealed (Table 1). Referrals for 
off-site HIV testing were offered by $52 \%$ of programs, and $8 \%$ of all programs reported no procedure in place for referral to HIV testing (Table 1). Condoms were not distributed by $39 \%$ of programs (Table 1). Reasons given were "no need" ( $\mathrm{N}=18,18 \%)$, lack of funds ( $\mathrm{N}=17,17 \%)$, and clinic policy prohibiting distribution $(\mathrm{N}=12,12 \%)$. Services corresponding to the state's ETE plan included offering HIV testing to clients ( $\mathrm{N}=35,35 \%)$, PrEP education ( $\mathrm{N}=33,32 \%)$, and PrEP prescriptions ( $\mathrm{N}=21,20 \%)$.

Whereas $25 \%$ of programs $(\mathrm{N}=25)$ reported that more than $75 \%$ of their HIV clients were receiving antiretroviral therapy (ART), $6 \%$ of programs $(\mathrm{N}=6)$ reported that none of their HIV clients were receiving ART, and 50\% of programs ( $\mathrm{N}=50)$ were unable to estimate how many of their HIV clients were receiving ART. Patient care coordinators for HIV-positive clients were available in $28 \%(\mathrm{~N}=28)$ of programs. Integration of HIV medical services with psychiatric services for HIV-positive clients was rated from 0 , none, to 4 , full integration. Twenty-two percent $(\mathrm{N}=14)$ of programs self-rated as having no integration, and 18\% ( $\mathrm{N}=13)$ rated themselves as fully integrated. Barriers to addressing HIVrelated needs were lack of training ( $\mathrm{N}=40,39 \%)$, lack of time $(\mathrm{N}=8,8 \%)$, client resistance $(\mathrm{N}=6,6 \%)$, and staff feeling overwhelmed by patients' comorbid conditions ( $N=5,5 \%)$.

HIV services for mental health clients were rated as either "essential" or "very important" by 69\% of programs, "somewhat important" by $23 \%$, and "not very important" or "unimportant" by $8 \%$ (Table 1). Geographic differences were found for 19 of the 30 (63\%) services we examined, with more reported HIV-related service delivery in urban than in suburban and rural areas.

Chi-square analysis of all comparable variables between current responses and data from similar surveys in 1997 (5) and 2004 (7) yielded some significant differences (Table 1). Since 1997, representation of rural sites increased (from $12 \%$ to $24 \%$ ), fewer programs served a patient census of under 100 (from $18 \%$ to $13 \%$ ), the proportion of programs serving over 500 patients per year almost doubled (from 35\% to $66 \%$ ), fewer programs had no patients known to have HIV/ AIDS (from $15 \%$ to $9 \%$ ), and more programs served over 100 patients known to be living with HIV/AIDS (from $8 \%$ to $23 \%$ ). Since 2004 , proportionally more programs reported no integration of HIV medical services with psychiatric services (from $\mathrm{N}=50,14 \%$ to $\mathrm{N}=14,22 \%$ ), or rated themselves as fully integrated (from $\mathrm{N}=46,13 \%$ to $\mathrm{N}=12,18 \%$ ).

\section{DISCUSSION}

Epidemiological evidence indicates that clients of mental health programs are at increased risk for HIV infection, and we found that nearly $70 \%$ of program directors rated HIVrelated services as either "essential" or "very important." However, most of New York's licensed outpatient mental health clinics are not optimized to meet the HIV-related needs of clients, even in regions of the state with moderate to high HIV case rates. Several significant findings emerged in comparing the current data with data from 1997 and 2004. More mental health programs have larger caseloads of patients known to have HIV or AIDS despite the 2017 sample comprising more rural agencies and the lack of case-finding processes (reported in $40 \%$ of programs).

We found that more programs assessed HIV risk as a routine part of the intake procedure, from $30 \%$ of programs in 2007 to $60 \%$ in 2017 . Increases in HIV testing were also found over the same period. Significantly more clinics either performed their own HIV testing or referred a client for such testing. The proportion of programs reporting that they had no procedure in place for HIV testing or referrals declined from $19 \%$ to $8 \%$. Patients with serious mental illness may continue to need HIV test counseling that takes their mental health conditions into account; such counseling is unlikely at HIV testing sites where counselors are not trained to work with people with serious mental illness.

Prevention and care services appear to have declined in outpatient mental health programs: $40 \%$ reported not providing condoms to clients who were unlikely to be able to afford them, reducing the likelihood of their use. The relatively high proportion of current programs that were unable to estimate clients' rates of HIV testing and ART initiation portrays the lack of reach of ETE into the main system of care for this population. It is critical to continue to offer both behavioral and biomedical approaches to prevent acquisition and transmission of HIV. PrEP, which is underutilized in mental health programs and nonpsychiatric settings alike, is offered to people with serious mental illness through only one in five mental health programs we surveyed, limiting access to one of the most efficacious HIV prevention interventions.

Data were provided by directors or their designees of programs whose e-mail addresses were provided to us by the New York State Office of Mental Health. Our response rate was in the acceptable range for online surveys, although the total number of programs eligible to be surveyed had reduced considerably since prior surveys were conducted. This reduction likely reflects consolidation of programs-we found that the total number of programs decreased while the proportion of programs serving more than 500 clients had nearly doubled-a trend that is also happening in other parts of the health care environment (15). The reduction also may be the result of shifting from a paper-based to an online survey method in 2017. The acceptable response rate we obtained supports the validity of our results (16); however, it was not possible to analyze differences between respondents and nonrespondents to ascertain the representativeness of participating programs, so results should be generalized with caution. On the other hand, rural counties were better represented in the current data than in prior surveys, possibly providing a more complete snapshot of HIV service provision in rural mental health programs than prior surveys did.

Data about how outpatient mental health programs are participating in New York's initiative to end the HIV epidemic 
are scarce. Our findings argue for further investigation into improved strategies for integrating services. Interagency activities between health and mental health departments could be initiated or bolstered to meet the needs of people with these co-occurring conditions, with particular attention to enhancing integrated services in suburban and rural areas and to improving surveillance and monitoring systems to illuminate which clients are accessing care in both systems.

\section{CONCLUSIONS}

People with serious mental illness receive some needed HIV services in public outpatient mental health programs. Integrated care models exist for providing basic medical care in mental health programs or basic care for common mental disorders in primary medical care (17). Clients with intensive medical and psychiatric needs may be unable to access a single setting that can meet their needs. New York's ETE initiative must expand to reach patients in this population and the providers who care for them.

\section{AUTHOR AND ARTICLE INFORMATION}

Washington Heights Community Service, New York State Psychiatric Institute (McKinnon, Alves-Bradford); Department of Psychiatry, Columbia University Vagelos College of Physicians and Surgeons (McKinnon, Alves-Bradford); Northeast/Caribbean AIDS Education and Training Center (Satriano, Cournos); Columbia University HIV Behavioral Health Training (Erby, Simonen, Gozzo, Robles Huang, Sposito, Tao, Zakoian, Zurita McKinnon); Columbia University Mailman School of Public Health (Jaafar, Cournos), all in New York. Send correspondence to Ms. K. McKinnon (kmm49@columbia.edu). Preliminary findings from this survey were presented in part at the annual meeting of the American Psychiatric Association, May 18-22, 2019, San Francisco.

This study was supported by the Health Resources and Services Administration, HIV/AIDS Bureau (U1OHA29291). The authors thank Marc Manseau, M.D., and Michael Compton, M.D., for acting as liaisons to the New York State Office of Mental Health licensed clinics and for offering input on survey content.

The authors report no financial relationships with commercial interests. Received August 19, 2019; revision received November 27, 2019; accepted January 22, 2020; published online March 10, 2020.

\section{REFERENCES}

1. Singh S, Song R, Johnson AS, et al: HIV incidence, prevalence, and undiagnosed infections in US men who have sex with men. Ann Intern Med 2018; 168:685-694

2. Hughes E, Bassi S, Gilbody S, et al: Prevalence of HIV, hepatitis B, and hepatitis $\mathrm{C}$ in people with severe mental illness: a systematic review and meta-analysis. Lancet Psychiatry 2016; 3:40-48

3. Bhugra D: The global prevalence of schizophrenia. PLoS Med 2005; 2:e151

4. Ending the AIDS Epidemic in New York State. Albany, New York State Department of Health, 2020. https://www.health.ny.gov/ diseases/aids/ending_the_epidemic. Accessed Aug 16, 2019

5. McKinnon K, Cournos F, Herman R, et al: AIDS-related services and training in outpatient mental health care agencies in New York. Psychiatr Serv 1999; 50:1225-1228

6. Satriano J, Rothschild RR, Steiner J, et al: HIV service provision and training needs in outpatient mental health settings. Psychiatr Q 1999; 70:63-74

7. Satriano J, McKinnon K, Adoff S: HIV service provision for people with severe mental illness in outpatient mental health care settings in New York. J Prev Interv Community 2007; 33:95-108

8. Shumway M, Mangurian C, Carraher N, et al: Increasing HIV testing in inpatient psychiatry. Psychosomatics 2018; 59:186-192

9. Remien RH, Stirratt MJ, Nguyen N, et al: Mental health and HIV/AIDS: the need for an integrated response. AIDS 2019; 33: 1411-1420

10. Kim S, Ades M, Pinho V, et al: Patterns of HIV and mental health service integration in New York State. AIDS Care 2014; 26: 1027-1031

11. Mauer BJ, Druss BG: Mind and body reunited: improving care at the behavioral and primary healthcare interface. J Behav Health Serv Res 2010; 37:529-542

12. Thorpe K, Jain S, Joski P: Prevalence and spending associated with patients who have a behavioral health disorder and other conditions. Health Aff 2017; 36:124-132

13. HIV Basics: U.S. Statistics. Washington, DC, US Department of Health and Human Services, 2019. https://www.hiv.gov/hiv-basics/ overview/data-and-trends/statistics. Accessed July 17, 2019

14. Nulty DD: The adequacy of response rates to online and paper surveys: what can be done? Assess Eval High Educ 2008; 33: 301-314

15. Gaynor M, Mostashari F, Ginsburg PB: Making health care markets work: competition policy for health care. JAMA 2017; 317:1313-1314

16. Morton SM, Bandara DK, Robinson EM, et al: In the 21st century, what is an acceptable response rate? Aust N Z J Public Health 2012; 36:106-108

17. Wulsin LR, Söllner W, Pincus HA: Models of integrated care. Med Clin North Am 2006; 90:647-677 